\title{
Evaluation of the corrosion protection of steel by anodic processing in metasilicate solution using the scanning vibrating electrode technique
}

\author{
J. Izquierdo ${ }^{1,2}$, B.M. Fernández-Pérez ${ }^{1}$, L. Martín-Ruíz ${ }^{1}$, V. Mena ${ }^{3}$, R. Rodríguez-Raposo ${ }^{1}$, J.J. \\ Santana $^{3}$, R.M. Souto ${ }^{1,2}$
}

${ }^{1}$ Department of Chemistry, University of La Laguna, P.O. Box 456, E-38200 La Laguna, Tenerife, Canary Islands, Spain

${ }^{2}$ Institute of Material Science and Nanotechnology, University of La Laguna, P.O. Box 456, E38200 La Laguna, Tenerife, Canary Islands, Spain

${ }^{3}$ Department of Process Engineering, University of Las Palmas de Gran Canaria, E-35017 Las Palmas de Gran Canaria, Canary Islands, Spain

\begin{abstract}
Anodic processing in metasilicate solution was investigated for the improvement of the corrosion resistance of various steels, namely F111 low alloy carbon and 304 stainless steels, as well as on galvanized steel cut edges. The efficiency of the prior electrochemical treatment for each material was tested during their exposure to naturally-aerated aqueous chloride solutions of different aggressiveness. Analysis was performed using the scanning vibrating electrode technique (SVET) in order to detect local ionic current distributions over the samples under study associated to the corrosion reactions. The onset of corrosion processes were greatly inhibited after anodic processing with metasilicate on both the low alloy carbon steel and the galvanized steel cut edge. Conversely, SVET analysis of unbiased 304 steel samples tested in $0.1 \mathrm{M}$ chloride-containing solution did not show differences between pristine and metasilicate-treated surfaces. Differences in the electrochemical reactivity between treated and non-treated 304 steel surfaces were only observed after partial removal of the corresponding passive layers under operator-controlled polarization.
\end{abstract}

Keywords: corrosion protection; steel; metasilicate ions; surface modification; anodic treatment; scanning vibrating electrode technique. 


\section{Introduction}

Due to its low toxicity, sodium silicates are used as corrosion inhibitor for iron-based materials in water supply networks [1]. Stable thin layers are rapidly formed onto the metal surfaces, that are favoured by the alkalization provoked by the silicate anions [2,3]. Rather than involving chemical reactions, inhibition is regarded to proceed through neutralization of charged particles, namely iron cations and silicate anions [4,5]. They may coagulate and adsorb on the metal surface, provided that corrosion products are first formed and precipitate. The observed electrochemical behaviour is typical of a two-interface system, where most of the formed iron cations remain as iron oxides and iron silicates, originating a polymerized silica layer through Fe-O-Si bonds [6,7]. This results not only in the inhibition of the anodic dissolution process, but also in the hindrance of the cathodic half-reaction involving oxygen reduction (i.e., mixed inhibitive behaviour), because the corrosion reaction preferentially occurs with hydrogen evolution even upon exposure to well-aerated electrolytes $[7,8]$.

Since corrosion must first occur for the silica layer to precipitate and be bound to the oxide layer, prior surface modification of the material involving silicate species have been attempted more recently. In this way, enhanced resistance against both metastable and stable pitting in chloridecontaining aqueous environment was found following prior anodic treatment of stainless steel in metasilicate solution [9]. This strategy overcame the limitation stemmed from the needed continuous interaction between the material and silicate salt solutions for the inhibitive properties to be exploited, thus eventually allowing this protection to continue in operation even in the absence of the inhibitor. Other surfaces which have proven to be protected by sodium silicate are zinc metal and galvanized layers, the latter used for the sacrificial anodic protection of iron-based structures. Thus, high inhibitive efficiency accompanied with the presence of silica, possibly as zinc silicates, was reported by Aramaki following an optimized treatment of zinc in sodium silicate solution [10]. This report contradicted the existing opinion that the treatment of zinc with sodium metasilicate did not provide further protective effects beyond the passivation due to the alkalization effect [3]. Multianalytical technique analysis has indeed shown the formation of a thin outer layer of polymerized silica attached to an inner layer containing zinc silicate over the galvanized steel [11-13]. The final layer structure of the protecting surface film varied with the actual treatment procedure performed, that involved electrochemical treatment and surface polarization for optimization purposes [11].

With independence of the metal-inhibitor system under consideration, both the inhibitor interaction and the eventual corrosion processes are initiated at micrometer or submicrometer scales, through the development of microcells associated to their dynamic electrochemical processes. Precise monitoring of these processes in this spatial range is mandatory to elucidate their 
mechanisms, as well as to improve the protective efficiencies of the inhibitors. In this context, the scanning vibrating electrode technique (SVET) is particularly helpful, because it images the ionic fluxes arising from metallic surfaces undergoing electrochemical degradation and its eventual hindrance as result of the implementation of corrosion protection methodologies [14,15]. Accurate characterization of galvanic corrosion processes [16-18], including those occurring at the cut edges of galvanized steel substrates [19-21], have been possible using this technique. In addition, SVET has proven to be particularly effective for the rapid screening of inhibitor efficiency for the corrosion protection of materials of technological interest [22-26]. Yet, the SVET has been scarcely employed for the characterization of the protective layers formed on metallic materials containing Si for chemical bonding. In fact, applications have been constrained to the characterization of a few pretreatments with organic-silane molecules [27], and $\mathrm{SiO}_{\mathrm{x}} / \mathrm{ZrO}_{\mathrm{x}}$ sol-gel coatings [28], the latter eventually further doped with encapsulated corrosion inhibitors to promote self-healing behaviour [28-30].

The present work reports on the enhanced corrosion protection operated on low alloy carbon steel, galvanized steel, and 304 stainless steel by anodic processing in sodium metasilicate solution. The effect of the surface modification on the corrosion behaviour of the three materials was spatially-resolved using SVET during their exposure to chloride-containing aqueous solution. The range of protection gained by the materials was determined in terms of the minimum aggressive conditions required by each system to experience corrosion.

\section{Experimental section}

Three different steel samples were considered in this work, namely, low alloy carbon steel (grade F111), galvanized low alloy carbon steel and 304 grade austenitic stainless steel. The compositions of the steels were determined by Spark Emission Spectrometry and are given in Table 1. The galvanized low alloy carbon steel consisted of $400 \mu \mathrm{m}$ steel substrate, $5 \mu \mathrm{m}$ chromate conversion layer, and $20 \mu \mathrm{m}$ of Aluzinc coating (composition 45\% Al + 55\% Zn). F111 and 304 steels were supplied as $1 \mathrm{~mm}$ thick sheets, and they were cut into metal strips of ca. $2 \mathrm{~mm} \times 1 \mathrm{~mm}$ section. Two strips of the same steel were embedded vertically in an insulating resin (Epofix kit, Struers, Ballerup, Denmark), with an approximate separation of $5 \mathrm{~mm}$ between them. In this way, both pristine and metasilicate-treated surfaces could be monitored in a single experiment. The metal strips were allowed to protrude at the rear of the mount to facilitate electrical connection to ensure either galvanic coupling or the application of a polarization. On the other hand, the galvanized steel sheet was cut into $4 \mathrm{~mm}$ width strips and mounted vertically in the Epofix resin to expose a cut edge of ca. $4 \mathrm{~mm} \times 450 \mu \mathrm{m}$ rectangular section. In this case, only one galvanized carbon steel strip was 
embedded per mould, because the length of the sample was enough to allow only a half of the surface to be treated in metasilicate solution, whereas the rest of the surface remained untreated. The electrode surface area was ground using a sequence of SiC papers up to 4000 grit, and finished with $0.3 \mu \mathrm{m}$ particle size alumina aqueous slurries prior to electrochemical processing following a procedure adapted from ref. [9]. After each polishing step, the samples were cleaned using ultrapure deionized water.

Anodic processing of the various steel samples was performed in $1.0 \mathrm{M}$ sodium metasilicate $\left(\mathrm{Na}_{2} \mathrm{SiO}_{3}\right)$ solution. For the sake of comparison, only half of the total metal exposed in the mounts was immersed in the treatment solution. This was accomplished by exposing either half of the length of the galvanized steel cut edge, or only one of the strips for the mounts containing the stainless and the carbon steels. The three-electrode electrochemical arrangement was completed using an $\mathrm{Ag} / \mathrm{AgCl} / 3 \mathrm{M} \mathrm{KCl}$ reference electrode, and a platinum ring as counter electrode. Potentiostatic control was accomplished using an EG\&G Princeton Applied Research potentiostat model 283A (Oak Ridge, TN, USA). The processing potential for 304 stainless steel and carbon steel samples was set at $-0.36 \mathrm{~V}$ vs. $\mathrm{Ag} / \mathrm{AgCl} / 3 \mathrm{M} \mathrm{KCl}$ following the indications given in ref. [9]. But in the case of the galvanized steel cut edge, a more negative potential was applied, namely $-0.65 \mathrm{~V}$ vs. Ag/AgCl/3M $\mathrm{KCl}$, to avoid eventual precipitation of zinc salts on the surface. The duration of the electrochemical treatment was 40 minutes in all cases. Upon completion of the treatment, the mounts were removed from the solution and thoroughly rinsed with ultrapure deionized water.

SVET measurements were performed using a setup manufactured by Applicable Electronics Inc. (Forestdale, MA, USA) and controlled by dedicated software. The sensing probes were $10 \mu \mathrm{m}$ Pt/Ir (80\%/20\%) wires insulated with paralene $C^{\circledR}$ and arced at the tip to expose the metal. These wires were platinized in order to produce a spherical platinum black deposit of 10-20 $\mu$ m diameter. A video camera connected to an optical microscope was included in the setup both to establish the probe to sample distance, and to follow the movement of the vibrating electrode over the sample during operation. Additionally, the video camera was employed to obtain optical images of the samples in situ, as to establish a correspondence between the images and the measured ionic current data. The mounts with the metallic samples embedded in resin were surrounded laterally by sellotape, thus creating a small container for the electrolyte solution, and the electrolyte covered the specimen under investigation by a ca. $4 \mathrm{~mm}$ liquid column. The electrochemical cell for SVET operation was completed with the inclusion of the corresponding microelectrodes, namely the spherical platinized probe and a Pt wire as reference electrode. A reference measurement with the microelectrode away from the active area was subtracted from the values measured during the scan. 
The measurements were made with the probe vibrating in a plane perpendicular to the sample at amplitude of $10 \mu \mathrm{m}$. The mean distance between the microelectrode and the sample surface was 60 $\mu \mathrm{m}$. Some selected experiments were performed on biased 304 stainless steel strips. In this case, an $\mathrm{Ag} / \mathrm{AgCl} / 3 \mathrm{M} \mathrm{KCl}$ reference electrode and a platinum ring counter electrode were added inside the small electrochemical cell, whereas the exposed metal strips were connected as the working electrode. Electrochemical control was performed with the EG\&G 283A potentiostat.

The chloride-containing media chosen to test the corrosion resistance of the steel samples were selected as a compromise between a sufficiently low conductivity electrolyte to satisfactorily resolve the potential gradients in the electrolyte resulting from the corrosion reactions on the metal, and enough chemical aggressiveness for differences in electrochemical activity between treated and non-treated surfaces to be distinguished. Though most experiments were performed with the metallic samples left at their spontaneous OCP in the electrolyte, selected experiments were also performed on biased 304 steel samples following polarization of the metal to reduce the oxide protective layer using the procedure described in ref. [31]. In brief, the procedure involved the potentiostatic application to the sample of a cathodic pulse for 6 seconds, subsequently followed by an anodic polarization at $+0.45 \mathrm{~V}$ vs. $\mathrm{Ag} / \mathrm{AgCl} / 3 \mathrm{M} \mathrm{KCl}$ to promote eventual pitting corrosion. During this anodic polarization, the current flowing through the substrate current was monitored using the potentiostat, whereas simultaneously recording the current density distributions over the centre of the metal surface using the probe of the SVET.

Traditional electrochemical characterization of pristine and metasilicate-treated steel samples was also performed using Tafel polarization analysis in the same test solutions employed in the SVET measurements. Potentiostatic control was accomplished using an EG\&G Princeton Applied Research potentiostat model 2263 (Oak Ridge, TN, USA). The metal samples were left unpolarized for $30 \mathrm{~min}$ in the corresponding test solution to attain a stable open circuit potential (OCP). Then, the cathodic and anodic Tafel branches were sequentially recorded by polarizing the sample from the OCP value to $\pm 0.25 \mathrm{~V}$ vs. the OCP.

The electrolyte solutions employed in this work were prepared using ultrapure deionized water (Milli-Q, Millipore) and sodium chloride, sodium metasilicate and hydrochloric acid (analytical grade reagents). All the experiments were performed in the naturally aerated solutions at ambient temperature (nominally $20^{\circ} \mathrm{C}$ ).

\section{Results and discussion}

\subsection{Scanning vibrating electrode technique}


The corrosion protection performance of the surface layers produced on various steel substrates by prior electrochemical anodization in metasilicate-containing solution was characterised by SVET. The efficiency of the anodization pre-treatment for each material was investigated by scanning the vibrating probe over the pristine and the metasilicate-treated steel surfaces while immersed in a chloride-containing solution of sufficient aggressivity for the onset of the corrosion processes. The composition of the chloride-containing media was selected as a compromise between a sufficiently low conductivity electrolyte, necessary to satisfactorily resolve the potential gradients in the electrolyte resulting from the corrosion reactions on the metal, and enough chemical aggressiveness for differences in electrochemical activity between treated and non-treated surfaces to be distinguished. A $10 \mathrm{mM} \mathrm{NaCl}$ solution was aggressive enough when either the galvanized steel cut edge or the low alloy steel were considered, and these materials were always monitored at their spontaneous OCP in the electrolyte. Yet, for the characterization of the 304 stainless steel more concentrated chloride solutions were necessary (i.e., $0.1 \mathrm{M} \mathrm{HCl}$ and $0.1 \mathrm{M} \mathrm{NaCl}$ ), and polarization of the samples was also required in some experiments in order to evidence differences in the electrochemical behaviour between non-treated and metasilicate-treated surfaces.

\subsubsection{The behaviour of low alloy carbon steel grade F111}

The effect of metasilicate pre-treatment on the corrosion resistance of low alloy carbon steel was characterised using epoxy mounts containing two metal strips separated approximately $1 \mathrm{~cm}$ between them. Prior to SVET imaging, one of the steel strips was immersed in the metasilicatecontaining solution and biased at $-0.36 \mathrm{~V}$ vs. $\mathrm{Ag} / \mathrm{AgCl} / \mathrm{KCl} 3 \mathrm{M}$ for 40 minutes. In this way, whereas one of the steel strips was subjected to surface modification by metasilicate, the other remained unmodified, thus presenting the pristine steel surface obtained after polishing and exposure to air.

SVET imaging was performed in $10 \mathrm{mM} \mathrm{NaCl}$ solution. Figure 1 depicts selected SVET images recorded over the two metal strips for various immersion times in the solution. Though no external bias was applied to the samples, two different surface conditions were explored in the same experiment. The experimental procedure consisted in first leaving both metal strips without electrical connection for $30 \mathrm{~min}$ as to attain their spontaneous OCP values in the electrolyte. Next, the two metal strips were electrically-connected at the rear at the mount, thus developing a mixed potential in the electrolyte. As expected, electrochemical activity related to the flux of ionic species was almost exclusively observed above the pristine strip in both electrical conditions. Almost from the beginning of the exposure of the samples to the test solution, the SVET map recorded over the pristine surface shows the onset of a localized corrosion process recorded as a burst of anodic current flow into the electrolyte (see Figure 1A). The same corroding spot continues active after the two metal strips were 
electrically connected (see Figure 1C), though there is an increase in both the magnitude of the recorded ionic currents and the surface covered by the anodic peak. One hour later, the SVET map depicted in Figure 1E shows that the activity in this corroding site has greatly diminished, possibly due to precipitation of corrosion products, a behaviour typically exhibited by pure iron (cf. Figure 2 in ref. [16]). In addition, another corroding site has been initiated almost at the other end of the metal strip, which corrodes with higher corrosion rates. Meanwhile, the metasilicate-treated surface provided only background noise signals at all times (see Figures 1B, D and F), indicating the formation of a sufficiently protective passive layer on the surface of the material. Moreover, the longer exposure of the materials to the aggressive media promoted the increase of activity registered over the non-treated metal but did not affect the surface which had been protected. Neither anodic nor cathodic activation of the previously anodized layer was recorded once electrically connected to the second surface, supporting that the resulting protective layer exhibits mixed anodic and cathodic behaviour, since not even under galvanic connection with a more active surface, which consequently freely corrodes by itself as if it was completely isolated [25].

The poorer corrosion resistance of the pristine surface compared to that modified in metasilicate solution was visualized even from the optical micrographs obtained using the optical camera installed in the equipment, as evidenced in Figure 2. The nucleation of various localized corrosion processes are seen on the non-treated material (cf. Figures 2A and B), whereas the strip anodised in metasilicate seemed to remain unaltered in the same environment (Figure 2C and D). Furthermore, the precipitation of corrosion products effectively blocking the corroding surface in the site that was activated first (cf. Figure 1A) is readily observable in Figure 2B.

\subsubsection{The behaviour of a galvanized steel cut edge}

In this case, only half of the length of the galvanized steel cut edge was immersed and treated in metasilicate solution at $-0.65 \mathrm{~V}$ vs. $\mathrm{Ag} / \mathrm{AgCl} / 3 \mathrm{M} \mathrm{KCl}$ as described in the Experimental Section. In this way, both pristine and metasilicate-treated areas are present along the cut edge, and they were simultaneously imaged by SVET during immersion in $10 \mathrm{mM} \mathrm{NaCl}$ solution. Figure 3A displays an optical micrograph of the cut edge exposed to the electrolyte, where the right side corresponds to the portion previously treated in the metasilicate solution (as indicated by a drawn ellipsoid). Figure 3CF contains a selection of the SVET images recorded with the elapse of time during exposure to the test solution. The maps recorded over 20 hours exhibit electrochemical activation of the system to occur almost exclusively from the middle to the left side of the cut edge, whereas the right side remains inactive or, for the most, it showed weak cathodic activity. In this case, though the protective film formed with metasilicate operated as a cathodic inhibitor towards corrosion, the strong driving 
force derived from the galvanic connection may induce a fraction of the iron surface to still present some cathodic acitivity. Besides, the potential applied during ex-situ treatment (i.e., $-0.65 \mathrm{~V}$ vs. $\mathrm{Ag} / \mathrm{AgCl} / \mathrm{KCl} 3 \mathrm{M}$ ) was more negative than that applied to both F111 and 304 steels, because the open circuit potential of the cut edge was more negative (around $-0.90 \mathrm{~V}$ vs. $\mathrm{Ag} / \mathrm{AgCl} / \mathrm{KCl} 3 \mathrm{M}$ ). As result, during the anodic pre-treatment, competing electrochemical reactions such as the oxygen reduction half-reaction may have occurred on the metal surface during the pre-treatment process. The observed results do not significantly change during 20 hours immersion, and only slight decrease in substrate activity is observed. The latter can be related to surface blocking by zinc precipitates mostly occurring on the non-treated areas of the cut edge [32,33]. These observations evidence that the herein applied $e x$-situ treatment, presumably aided by the self-healing effect of the galvanized layer [20,21,33], results in a rather attractive and promising route for the protection of galvanized structures of great importance in the building environment.

\subsubsection{The behaviour of 304 grade stainless steel}

Conversely to the behaviour of low alloy carbon steel surfaces or a galvanized steel cut edge, differences in electrochemical activity between pristine and metasilicate-treated strips could not be observed by SVET while left unbiased in the test electrolyte, even in more aggressive test environments such as $0.1 \mathrm{M} \mathrm{NaCl}$ and $0.1 \mathrm{M} \mathrm{HCl}$. Therefore, the application of an anodic bias to both metal strips was next investigated, a procedure previously employed to distinguish between austenite stainless steels of different grades [34]. Figure 4A shows an optical micrograph of the two strips, where the strip treated with metasilicate is located at the bottom of the image. Current density distributions were monitored over 304 stainless steel surfaces exposed to $0.1 \mathrm{M} \mathrm{HCl}$ media whereas the samples were biased using a sequence of increasingly positive potential values. Since both strips were electrically connected at the rear of the mount, they were polarized at the same potential by using a potentiostat. Only background noise was observed when the samples were either left unpolarized or polarized up to $0 \mathrm{~V}$ vs. $\mathrm{Ag} / \mathrm{AgCl} / 3 \mathrm{M} \mathrm{KCl}$ (not shown). But substrate polarization at $+0.05 \mathrm{~V}$ vs. Ag/AgCl/3M KCl evidenced electrochemical activation with the nucleation of corrosion pits on both metallic surfaces, though one of them was prior treated with metasilicate (see Figure 4B). Greater anodic ionic current flows were recorded when the system was polarized at $+0.30 \mathrm{~V}$ vs. $\mathrm{Ag} / \mathrm{AgCl} / 3 \mathrm{M} \mathrm{KCl}$ as shown in Figure 4C. In this case, ionic current density values in the order of $\mathrm{mA} \mathrm{cm}{ }^{-2}$ were measured, showing the occurrence of propagating corrosion pits on both metal strips. Yet, SVET imaging in $0.1 \mathrm{M} \mathrm{HCl}$ did not allow detection of any electrochemical difference between the two surfaces despite prior surface modification operated to one of them. It seems the electrolyte media was too aggressive for such testing, and the protection provided by the anodization procedure 
was not sufficient when passive layer breakdown was promoted by applying a polarization to the samples. These observations may seem to contradict the previous report that this treatment produced greater resistance on 304 steel against metastable pitting [9] (which is the precursor stage to propagating pitting corrosion) as well as in the pitting corrosion potential. At this stage, spatial resolution through sample miniaturisation might thus be considered a more sensitive technique for the determination of pitting susceptibility after surface modification treatments compared to SVET in such an aggressive test environment. It must be noticed that the experiments reported herein were performed in an acid solution of rather high ionic conductivity, which may compromise the SVET sensibility. Though the acidity seems then to be critical for the induction of localized corrosion, the decrease of current fluctuation in the metastable regime was achieved in ref. [9] under exposure to less concentrated chloride solutions (namely, $\left[\mathrm{Cl}^{-}\right]=0.025 \mathrm{M}$ ) of the same acidity, at which no active corrosion occurred. Since SVET is not capable to image the highly localized and fast metastable activation that occurs down to the millisecond range, the only option to visualize any difference in electrochemical activation between treated and non-treated surfaces using SVET requires the induction of active corrosion.

An alternate methodology for the investigation of corrosion processes on 304 stainless steel under anodic polarization using SVET was recently proposed [31]. It involves the previous electrochemical reduction of the passive oxide layer in order to induce pitting with small overpotentials. Aggressiveness of the solution was then reduced by conducting the experiment in 0.1 $\mathrm{M} \mathrm{NaCl}$, and representative SVET images done are depicted in Figure 5. As expected from previous works [31,35,36], no stable pitting corrosion was detected for samples biased at $+0.40 \mathrm{~V}$ vs. $\mathrm{Ag} / \mathrm{AgCl} / 3 \mathrm{M} \mathrm{KCl}$, on neither treated nor non-treated steel surfaces (cf. Figure 5B). However, the application of a $6 \mathrm{~s}$ potentiostatic pulse at $-1.50 \mathrm{~V}$ vs. $\mathrm{Ag} / \mathrm{AgCl} / 3 \mathrm{M} \mathrm{KCl}$, immediately followed by anodic polarization at the same $+0.40 \mathrm{~V}$ vs. $\mathrm{Ag} / \mathrm{AgCl} / 3 \mathrm{M} \mathrm{KCl}$ value, resulted in the formation of a corroding pit over both surfaces, what were imaged by SVET as shown in Figure 5C. The justification for this behaviour is the electrochemical reduction of the oxide passive layer during the cathodic pulse, as it was characterized for the bare steel surface without metasilicate protection [31]. The same procedure has been followed in this work to investigate any influence of the metasilicate treatment on the susceptibility towards corrosion of the 304 steel. Thus, a series of short cathodic pulses followed by anodic polarization at $+0.40 \mathrm{~V}$ vs. $\mathrm{Ag} / \mathrm{AgCl} / 3 \mathrm{M} \mathrm{KCl}$ were applied to the substrate. Both the total current flowing through the two strips and the local ionic current densities on the metasilicate-treated strip were recorded as shown in Figure 6. Figures 6A and B show the SVET current density probe and the global substrate current recorded with substrate biased at +0.40 $\mathrm{V}$ vs. Ag/AgCl/3M KCl following the application of various cathodic pulses for $6 \mathrm{~s}$. No evidence of 
local activation was encountered during the polarization at this anodic overpotential within the first 60 seconds, though both graphs show increasing substrate currents when pulse was more cathodic than $-1.30 \mathrm{~V}$ vs. $\mathrm{Ag} / \mathrm{AgCl} / 3 \mathrm{M} \mathrm{KCl}$. This behaviour is different from that previously reported for the pristine material, because the cathodic pulse required to promote stable pitting corrosion only amounted $-1.00 \mathrm{~V}$ vs. Ag/AgCl/3M KCl (cf. Figure 5 in [31]). This is thus regarded an indication of the greater stability of the passive layer formed on the steel during its anodization in the metasilicate solution. The observation of a propagating pit in the SVET image of this surface required longer durations of the anodic polarization following the cathodic pulse. This is evidenced in Figure 6C corresponding to the SVET image acquired over a previously treated 304 stainless steel surface, which was cathodically polarized at $-1.40 \mathrm{~V}$ vs. $\mathrm{Ag} / \mathrm{AgCl} / 3 \mathrm{M} \mathrm{KCl}$ for $6 \mathrm{~s}$ before being anodically biased again at $+0.40 \mathrm{~V}$ vs. Ag/AgCl/3M KCl. The longer time needed for the scan acquisition permitted the evolution of a localized anodic area on the biased surface. Indeed, this scan corresponds to the second one recorded using the same sequence of $6 \mathrm{~s}$ cathodic pulse and subsequent anodic polarization. The first scan evidenced substrate activation from the trace of the average current recorded with the potentiostat, though the active corroding site was not be imaged at that stage most probably because it was actually activated after the vibrating probe had already passed above it.

\subsection{Tafel polarization tests}

For the sake of comparison, the corrosion protection supplied to the various steels by anodic processing in metasilicate solution was also characterized using Tafel polarization tests. Figure 7 depicts the Tafel polarization plots recorded for the various steel simples during immersion in the same electrolytes used above for the SVET characterization. Tafel analysis of both the anodic and cathodic branches of the polarization curves delivered values for the corrosion current densities $(j$ cor), and Tafel slopes $\left(\beta_{\mathrm{a}}, \beta_{\mathrm{c}}\right)$ in addition to the determined open circuit potential $\left(E_{\mathrm{cor}}\right)$ values. Polarization resistance $\left(R_{\mathrm{p}}\right)$ values were also obtained from the application of the Stern-Geary equation [37]. The electrochemical parameters obtained from the Tafel analysis of both pristine and metasilicate-treated steels are listed in Table 2. It is observed that anodic processing in metasilicate solution produced metal surfaces with enhanced polarization resistance and smaller corrosion currents in all cases. The efficiency $\left(S_{\mathrm{w}}\right)$ of the corrosion protection produced by anodic processing on the various steels can be estimated from the increase of the polarization resistance values for each material as given by: 


$$
S_{P}=\frac{R_{p}-R_{p 0}}{R_{p}} \times 100
$$

where $R_{\mathrm{p} 0}$ and $R_{\mathrm{p}}$ are the electrode polarization resistances determined with the pristine and the treated steel samples, respectively. High protection efficiency values were found for both grade F111 and galvanized steels (namely 97.8\% and 81.5\%, respectively. Though the protection efficiencies determined in the case of 304 stainless steel samples were smaller, $77.8 \%$ in $0.1 \mathrm{M} \mathrm{HCl}$ and $47.8 \%$ in $0.1 \mathrm{M} \mathrm{NaCl}$, the occurrence of a significant improvement of the corrosion protection of the stainless steel was also observed.

\section{Conclusions}

From the experiments described herein, the following conclusions are derived:

Anodic processing of steels in the presence of metasilicate ions produces surface films with greater corrosion resistance, as confirmed by multiscale electrochemical monitoring using Tafel polarization analysis and the scanning vibrating electrode technique.

The anodic and cathodic reactions occurring on the surface of various steel grades subjected to prior anodic treatment in metasilicate solution for enhanced corrosion protection, were imaged using SVET. This method involves combined selection of the aggressiveness of the test environment and eventual application of sample polarization for the electrochemical activation of the samples. As result, the effectiveness of the protection treatment could be monitored for the different materials under consideration.

In the case of grade F111 steel, enhanced corrosion protection by prior anodic treatment in metasilicate solution is readily observed from the SVET images recorded from the unbiased samples immersed in a chloride-containing solution. Neither anodic nor cathodic activity can be detected above the previously treated sample, conversely to the behaviour of the pristine steel exposed to the same test electrolyte. This may confirm that silicate conversion layers produces mixed cathodic-anodic inhibitive effect.

When a cut edge of galvanized steel partially treated by anodization in metasilicate solution is exposed to an aggressive medium, only the surface portion that was not treated in metasilicate solution undergoes degradation, and electrochemical activity is mainly encountered in this region. This observation supports also the mixed behaviour character of the inhibitor treatment.

> The improvement in pitting resistance of stainless steel surfaces by prior anodic treatment in metasilicate could not be distinguished by SVET on either non-biased and anodically polarized samples, because this method would require the effective breakdown of the passive layers in the 
pitting corrosion regime for imaging. Yet, the enhanced resistance of the surface layers formed by mild anodizing in sodium metasilicate was monitored through their persistence against electroreduction in chloride-containing electrolyte.

\section{Acknowledgments}

This work was financially supported by the Spanish Ministry of Economy and Competitiveness (MINECO, Madrid, Spain) jointly with the European Regional Development Fund (Brussels, Belgium) under Grant CTQ2012-36787. The award of Research Training Grants to J.I. by the Spanish Ministry of Education (Programa de Formación de Personal Investigador, Madrid, Spain), and to B.M.F.-P. by Fundación Cajacanarias - La Caixa (Santa Cruz de Tenerife, Spain) are greatly appreciated.

\section{References}

1. American Water Works Association / American National Standard Institute B404-2014 Standard.

2. Select Committee on GRAS Substances, Evaluation of the Health Aspects of Certain Silicates as Food Ingredients, SCOGS-61, Federation of American Societies for Experimental Biology, NTIS Publication 301-402/AS, Springfield, VA, 1979, p. 4.

3. C.P. Hill, A.F. Cantor (Eds.), Internal Corrosion Impacts in Drinking Water Distribution Systems, AWWA Manual M58, first edition, American Water Works Association, Denver, CO, 2011.

4. L. Lehrman, H.L. Shuldener, The role of sodium silicate in inhibiting corrosion by film formation on water piping, Journal of the American Water Works Association 43 (1951) 175188.

5. C.C. Davis, H.-W. Chen, M. Edwards, Modeling silica sorption to iron hydroxide, Environmental Science and Technology 36 (2002) 582-587.

6. V. Deodeshmukh, A. Venugopal, D. Chandra, A. Yilmaz, J. Daemen, D.A. Jones, S. Lea, M. Engelhard, X-ray photoelectron spectroscopic analyses of corrosion products formed on rock bolt carbon steel in chloride media with bicarbonate and silicate ions, Corrosion Science 46 (2004) 2629-2649.

7. M. Salasi, T. Shahrabi, E. Roayaei, M. Aliofkhazraei, The electrochemical behaviour of environment-friendly inhibitors of silicate and phosphonate in corrosion control of carbon steel in soft water media, Materials Chemistry and Physics 104 (2007) 183-190.

8. J.C. Rushing, L.S. McNeill, M. Edwards, Some effects of aqueous silica on the corrosion of iron, Water Research 37 (2003) 1080-1090. 
9. G.T. Burstein, R.M. Souto, Improvement in pitting resistance of stainless steel surfaces by prior anodic treatment in metasilicate solution, Journal of the Electrochemical Society 151 (2004) B537-B542.

10. K. Aramaki, The inhibition effects of chromate-free, anion inhibitors on corrosion of zinc in aerated 0.5 M NaCl, Corrosion Science 43 (2001) 591-604.

11. B. Veeraraghavan, D. Slavkov, S. Prabhu, M. Nicholson, B. Haran, B. Popov, B. Heimann, Synthesis and characterization of a novel non-chrome electrolytic surface treatment process to protect zinc coatings, Surface and Coatings Technology 167 (2003) 41-51.

12. M.-R. Yuan, J.-T. Lu, G. Kong, Effect of $\mathrm{SiO}_{2}: \mathrm{Na}_{2} \mathrm{O}$ molar ratio of sodium silicate on the corrosion resistance of silicate conversion coatings, Surface and Coatings Technology 204 (2010) 1229-1235.

13. M.-R. Yuan, J.-T. Lu, G. Kong, C.-S. Che, Effect of silicate anion distribution in sodium silicate solution on silicate conversion coatings of hot-dip galvanized steels, Surface and Coatings Technology 205 (2011) 4466-4470.

14. S. Rossi, M. Fedel, F. Deflorian, M.C. Vadillo, Localized electrochemical techniques: Theory and practical examples in corrosion studies, Comptes Rendus Chimie 11 (2008) 984-994.

15. R.S. Lillard, Scanning electrode techniques for investigating near-surface solution current densities, in: P. Marcus, F. Mansfeld (Eds.), Analytical Methods in Corrosion Science and Engineering, CRC Press, Boca Raton, FA, 2006, pp. 571-604.

16. A.M. Simões, A.C. Bastos, M.G.S. Ferreira, Y. González-García, S. González, R.M. Souto, Use of SVET and SECM to study the galvanic corrosion of an iron-zinc cell, Corrosion Science 49 (2007) 726-739.

17. F. Thébault, B. Vuillemin, R. Oltra, C. Allely, K. Ogle, Modeling bimetallic corrosion under thin electrolyte films, Corrosion Science 53 (2011) 201-207.

18. J. Izquierdo, L. Nagy, S. González, J.J. Santana, G. Nagy, R.M. Souto, Resolution of the apparent experimental discrepancies observed between SVET and SECM for the characterization of galvanic corrosion reactions, Electrochemistry Communications 27 (2013) 50-53.

19. D.A. Worsley, D. Williams, L.S.G. Ling, Mechanistic changes in cut-edge corrosion induced by variation of organic coating porosity, Corrosion Science 43 (2001) 2335-2348.

20. F. Thébault, B. Vuillemin, R. Oltra, K. Ogle, C. Allely, Investigation of self-healing mechanism on galvanized steels cut edges by coupling SVET and numerical modelling, Electrochimica Acta 53 (2008) 5226-5234. 
21. A.M. Simões, J.C.S. Fernandes, Studying phosphate corrosion inhibition at the cut edge of coil coated galvanized steel using the SVET and EIS, Progress in Organic Coatings 69 (2010) 219224.

22. M.J. Franklin, D.C. White, H.S. Isaacs, A study of carbon steel corrosion inhibition by phosphate ions and by an organic buffer using a scanning vibrating electrode, Corrosion Science 33 (1992) 251-260.

23. M. Reffass, R. Sabot, M. Jeannin, C. Berziou, Ph. Refait, Effects of $\mathrm{NO}_{2}{ }^{-}$ions on localised corrosion of steel in $\mathrm{NaHCO}_{3}+\mathrm{NaCl}$ electrolytes, Electrochimica Acta 52 (2007) 7599-7606.

24. S. Kallip, A.C. Bastos, M.L. Zheludkevich, M.G.S. Ferreira, A multi-electrode cell for highthroughput SVET screening of corrosion inhibitors, Corrosion Science 52 (2010) 3146-3149.

25. J. Izquierdo, L. Nagy, J.J. Santana, G. Nagy, R.M. Souto, A novel microelectrochemical strategy for the study of corrosion inhibitors employing the scanning vibrating electrode technique and dual potentiometric/amperometric operation in scanning electrochemical microscopy: Application to the study of the cathodic inhibition by benzotriazole of the galvanic corrosion of copper coupled to iron, Electrochimica Acta 58 (2011) 707-716.

26. S. Kallip, A.C. Bastos, K.A. Yasakau, M.L. Zheludkevich, M.G.S. Ferreira, Synergistic corrosion inhibition on galvanically coupled metallic materials, Electrochemistry Communications 20 (2012) 101-104.

27. M.F. Montemor, A.M. Cabral, M.L. Zheludkevich, M.G.S. Ferreira, The corrosion resistance of hot dip galvanized steel pretreated with Bis-functional silanes modified with microsilica, Surface and Coatings Technology 200 (2006) 2875-2885.

28. D. Borisova, H. Möhwald, D.G. Shchukin, Mesoporous silica nanoparticles for active corrosion protection, ACS Nano 5 (2011) 1939-1946.

29. W. Trabelsi, P. Cecilio, M.G.S. Ferreira, M.F. Montemor, Electrochemical assessment of the self-healing properties of Ce-doped silane solutions for the pre-treatment of galvanised steel substrates, Progress in Organic Coatings 54 (2005) 276-284.

30. M.F. Montemor, M.G.S. Ferreira, Cerium salt activated nanoparticles as fillers for silane films: Evaluation of the corrosion inhibition performance on galvanised steel substrates, Electrochimica Acta 52 (2007) 6976-6987.

31. J. Izquierdo, L. Martín-Ruíz, B.M. Fernández-Pérez, R. Rodríguez-Raposo, J.J. Santana, R.M. Souto, Scanning microelectrochemical characterization of the effect of polarization on the localized corrosion of 304 stainless steel in chloride solution, Journal of Electroanalytical Chemistry 728 (2014) 148-157. 
32. K. Ogle, V. Baudu, L. Garrigues, X. Philippe, Localized electrochemical methods applied to cut edge corrosion, Journal of the Electrochemical Society 147 (2000) 3654-3660.

33. R.M. Souto, B. Normand, H. Takenouti, M. Keddam, Self-healing processes in coil coated cladding studied by the scanning vibrating electrode, Electrochimica Acta 55 (2010) 4551-4557.

34. J. Izquierdo, L. Martín-Ruíz, B.M. Fernández-Pérez, L. Fernández-Mérida, J.J. Santana, R.M. Souto, Imaging local surface reactivity on stainless steels 304 and 316 in acid chloride solution using scanning electrochemical microscopy and the scanning vibrating electrode technique, Electrochimica Acta 134 (2014) 167-175.

35. S. Frangini, A. Masci, A.D. Bartolomeo, $\mathrm{Cr}_{7} \mathrm{C}_{3}$-based cermet coating deposited on stainless steel by electrospark process: structural characteristics and corrosion behaviour, Surface and Coatings Technology 149 (2002) 279-286.

36. T. Zhang, D.Y. Li, The effect of $\mathrm{YCl}_{3}$ and $\mathrm{LaCl}_{3}$ additives on wear of 1045 and 304 steels in a dilute chloride solution, Materials Science and Engineering: A 345 (2003) 179-189.

37. M. Stern, A.L. Geary, Electrochemical polarization: I. A theoretical analysis of the shape of polarization curves, Journal of the Electrochemical Society 104 (1957) 56-63.

Table 2. Effect of anodic processing in metasilicate solution on the corrosion resistance of various steels considered in this work. The electrochemical parameters were determined from Tafel analysis of the metal samples immersed in the test solutions employed for their characterization using the scanning vibrating electrode technique.

\begin{tabular}{lccccccc}
\hline $\begin{array}{l}\text { Steel type / } \\
\text { pretreatment with } \\
\text { metasilicate }\end{array}$ & Test solution & $\begin{array}{c}E_{\text {corr }} / \mathrm{V} \\
\text { vs. SCE }\end{array}$ & $\begin{array}{c}j_{\text {corr }} / \mathrm{nA} \\
\mathrm{cm}^{-2}\end{array}$ & $\begin{array}{c}\beta_{\mathrm{a}} / \mathrm{mV} \\
\mathrm{decade}^{-1}\end{array}$ & $\begin{array}{c}-\beta_{\mathrm{c}} / \mathrm{mV} \\
\mathrm{decade}^{-1}\end{array}$ & $\begin{array}{c}R_{\mathrm{p}} / \mathrm{k} \Omega \\
\mathrm{cm}^{2}\end{array}$ & $\begin{array}{c}\text { Protection } \\
\text { efficiency (\%) }\end{array}$ \\
\hline F111 / non-treated & $10 \mathrm{mM} \mathrm{NaCl}$ & -0.629 & 512 & 140.78 & 251.79 & 7.65 & \\
F111 / treated & $10 \mathrm{mM} \mathrm{NaCl}$ & -0.435 & 72.6 & 306.47 & 73.56 & 354.7 & 97.8 \\
$\begin{array}{l}\text { Galvanized / non- } \\
\text { treated }\end{array}$ & $10 \mathrm{mM} \mathrm{NaCl}$ & -1.096 & 21620 & 130.13 & 125.99 & 1.29 & \\
$\begin{array}{l}\text { Galvanized / treated } \\
304 \text { / non-treated }\end{array}$ & $10 \mathrm{mM} \mathrm{NaCl}$ & -1.099 & 3910 & 80.72 & 281.69 & 6.97 & 81.5 \\
304 / treated & $0.1 \mathrm{M} \mathrm{NaCl}$ & -0.192 & 100 & 251.64 & 101.76 & 306.6 & \\
304 / non-treated & $0.1 \mathrm{M} \mathrm{NaCl}$ & -0.289 & 61.5 & 221.48 & 133.04 & 587.0 & 47.8 \\
304 / treated & $0.1 \mathrm{M} \mathrm{HCl}$ & -0.323 & 4380 & 99.90 & 118.35 & 5.37 & \\
\hline & $0.1 \mathrm{M} \mathrm{HCl}$ & -0.345 & 800 & 466.14 & 49.10 & 24.18 & 77.8 \\
\hline
\end{tabular}



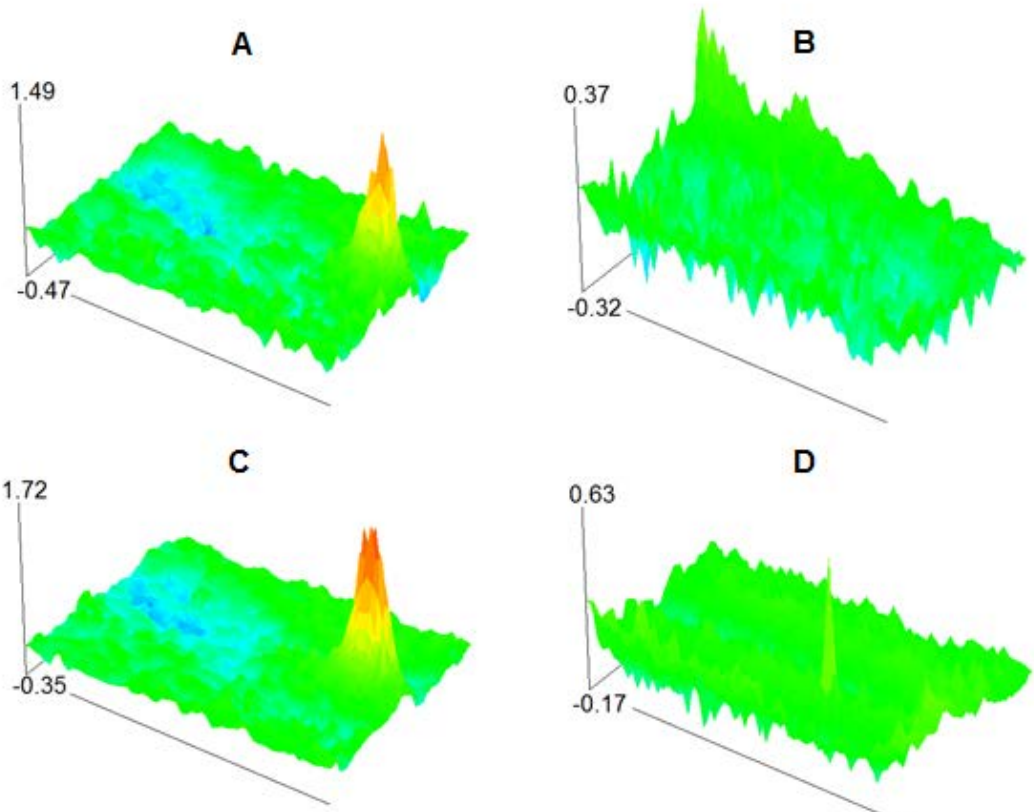

D
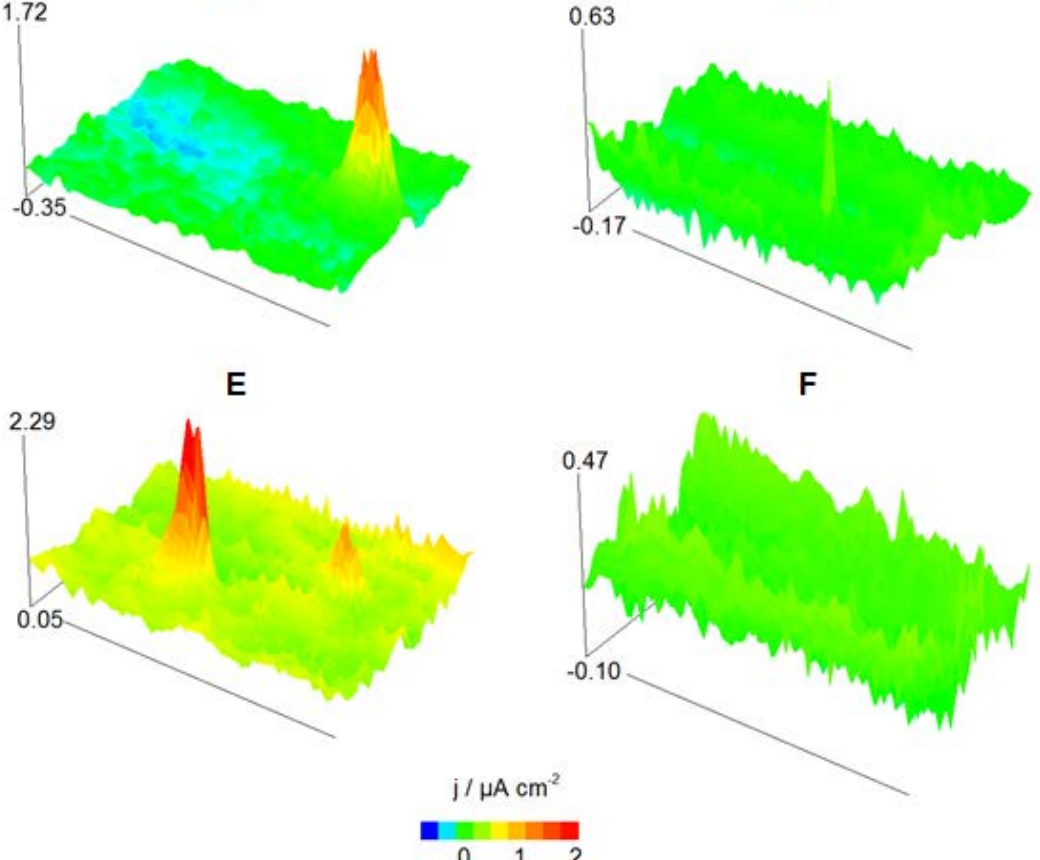

Figure 1

SVET images of two grade F111 steel strips immersed in $10 \mathrm{mM} \mathrm{NaCl}$ (resistivity, $930 \Omega \mathrm{cm}$ ), namely $(\mathrm{A}, \mathrm{C}, \mathrm{E})$ non-treated, and $(\mathrm{B}, \mathrm{D}, \mathrm{F})$ anodically pretreated in metasilicate solution. The two metal strips were initially left without electrical connection for $30 \mathrm{~min}$, and then galvanically coupled for the remaining of the experiment. The SVET images were recorded: $(A, B)$ at the beginning of their immersion in the test electrolyte (i.e., while the two samples were left at their corresponding OCP values in the electrolyte); (C,D) immediately after establishing an electrical connection between the two metal strips; (E,F) 60 min after electrical connection between the two metal strips. The images represent, in $X$ and $Y$ directions: (A,C,E) $1200 \mu \mathrm{m} \times 3400 \mu \mathrm{m}$, and (B,D,F) $3000 \mu \mathrm{m} \times 1560$ $\mu \mathrm{m}$. Values of $Z$ axis: Ionic current, $\mu \mathrm{A} \mathrm{cm}{ }^{-2}$. Mean probe-substrate distance: $60 \mu \mathrm{m}$. 

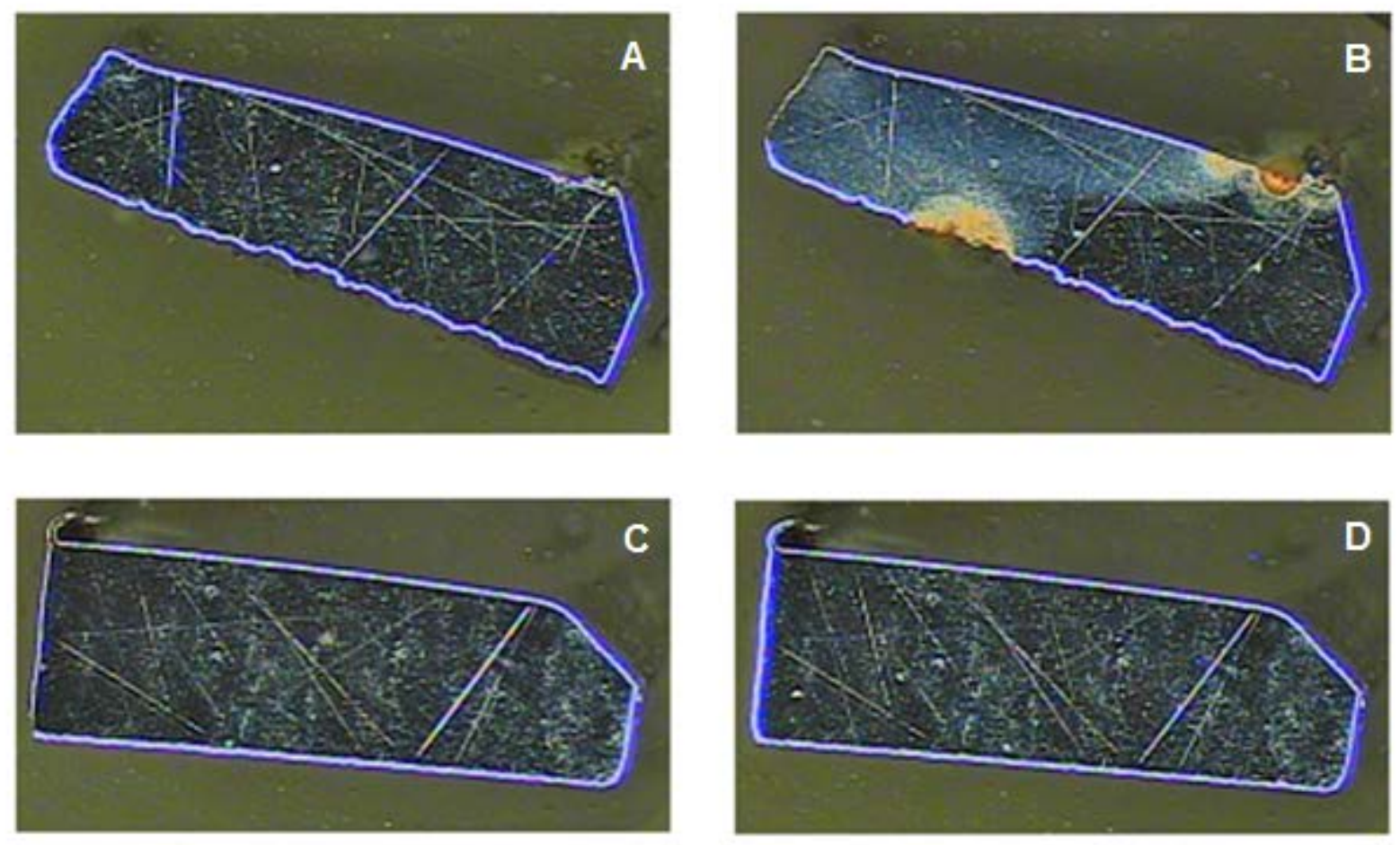

Figure 2

Optical micrographs of the grade F111 steel samples immersed in $10 \mathrm{mM} \mathrm{NaCl}$ while recording the SVET images given in Figure 1. Metal strips: $(A, B)$ non-treated, and $(C, D)$ treated in metasilicate solution. The micrographs were taken: $(A, C)$ immediately following the addition of the test solution to the small electrochemical cell containing the samples at the bottom; $(B, D)$ after recording the SVET images given in Figures 1E and F. 


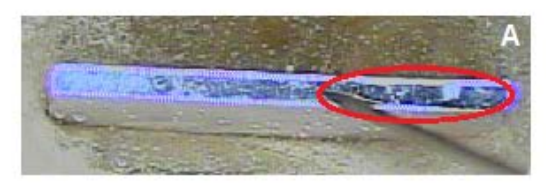

C

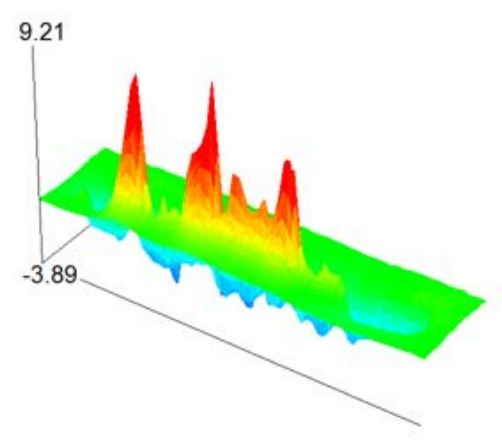

E

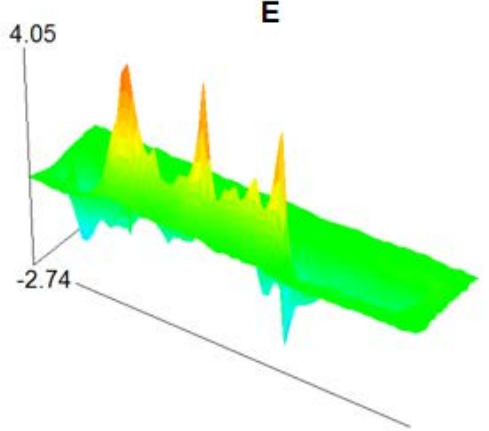

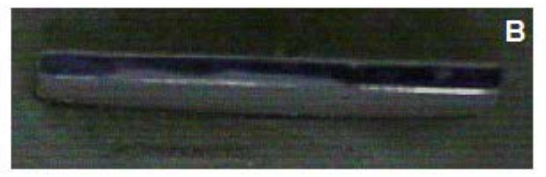

D

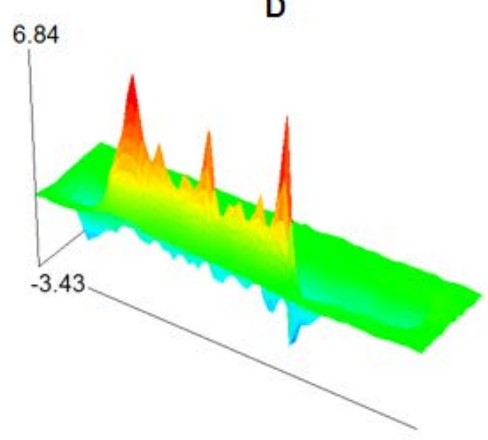

F

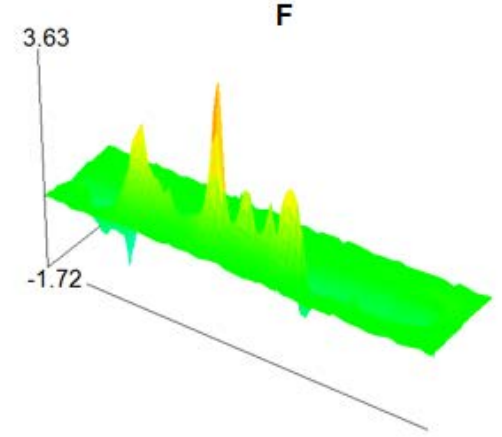

$\mathrm{j} / \mu \mathrm{A} \mathrm{cm}^{2}$

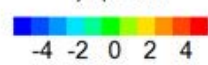

Figure 3

(A,B) Optical micrographs and (C-F) SVET images of a low alloy galvanized cut edge in $10 \mathrm{mM}$ $\mathrm{NaCl}$ (resistivity, $930 \Omega \mathrm{cm}$ ). Immersion time: (A,C) 0, (D) 2, (E) 5, and (B,F) 11 hours. The images represent $7400 \mu \mathrm{m} \times 1230 \mu \mathrm{m}$ in $X$ and $Y$ directions. Values of $Z$ axis: Ionic current, $\mu \mathrm{A} \mathrm{cm}^{-2}$. Mean probe-substrate distance: $60 \mu \mathrm{m}$. The ellipse drawn in (A) indicates the portion of the cut edge that was anodized in metasilicate solution. 

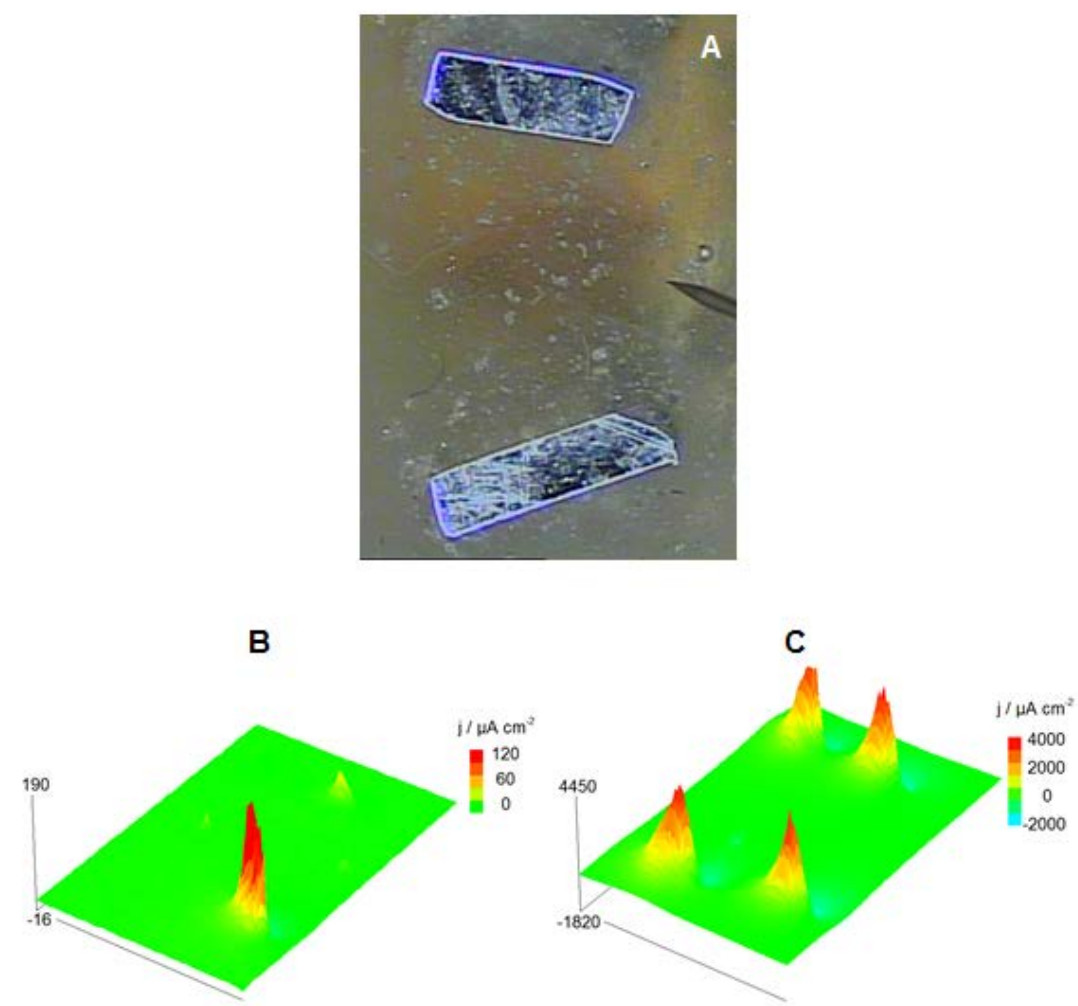

\section{Figure 4}

(A) Optical micrograph and (B,C) SVET images of two 304 stainless steel strips immersed in $0.1 \mathrm{M}$ $\mathrm{HCl}$ (resistivity $33.5 \Omega \mathrm{cm}$ ). The strip located at the bottom of the micrograph was subjected to prior anodic treatment in metasilicate solution. Polarization conditioning of the steel specimens: (B) +0.05 , and $(\mathrm{C})+0.30 \mathrm{~V}$ vs. $\mathrm{Ag} / \mathrm{AgCl} / 3 \mathrm{M} \mathrm{KCl}$. The images represent $5160 \mu \mathrm{m} \times 7900 \mu \mathrm{m}$ in $X$ and $Y$ directions. Values of $Z$ axis: Ionic current, $\mu \mathrm{A} \mathrm{cm}{ }^{-2}$. Mean probe-substrate distance: $60 \mu \mathrm{m}$. 

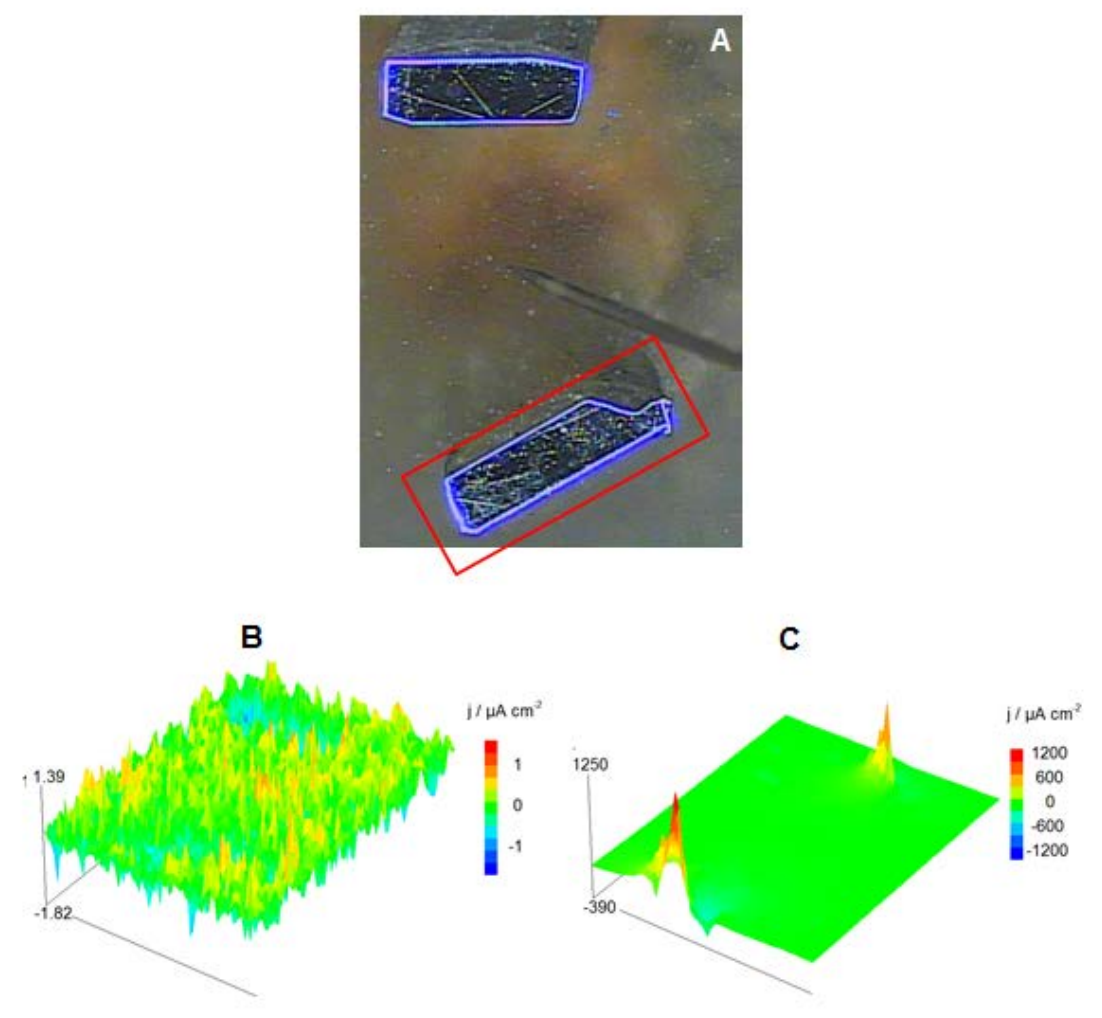

\section{Figure 5}

(A) Optical micrograph and (B,C) SVET images of two 304 stainless steel strips immersed in $0.1 \mathrm{M}$ $\mathrm{NaCl}$ (resistivity $92.8 \Omega \mathrm{cm}$ ). The strip located at the bottom of the micrograph was subjected to prior anodic treatment in metasilicate solution. SVET images were recorded while the steel strips were polarized at $+0.40 \mathrm{~V}$ vs. $\mathrm{Ag} / \mathrm{AgCl} / 3 \mathrm{M} \mathrm{KCl}$, either (B) before or (C) after the application of a cathodic pulse at $-1.50 \mathrm{~V}$ vs. $\mathrm{Ag} / \mathrm{AgCl} / 3 \mathrm{M} \mathrm{KCl}$ during $6 \mathrm{~s}$. The images represent $5200 \mu \mathrm{m} \times 7130$ $\mu \mathrm{m}$ in $X$ and $Y$ directions. Values of $Z$ axis: Ionic current, $\mu \mathrm{A} \mathrm{cm}^{-2}$. Mean probe-substrate distance: $60 \mu \mathrm{m}$. The rectangle drawn in (A) indicates the surface covered by the SVET image in Figure 6C. 

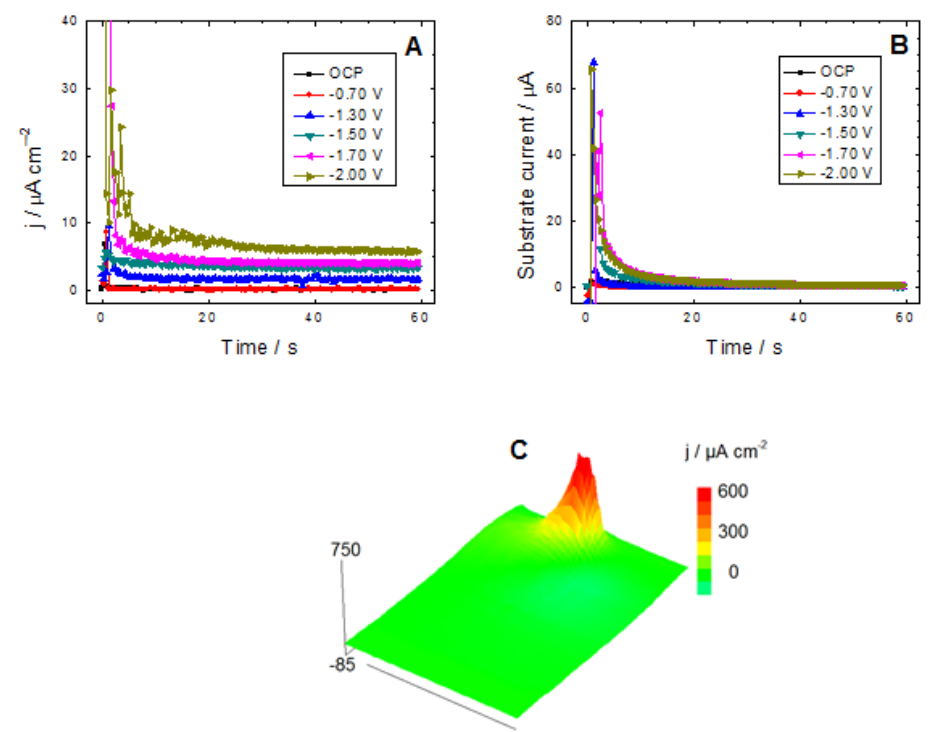

\section{Figure 6}

Time evolution of the (A) local and (B) average currents flowing during the immersion in $0.1 \mathrm{M}$ $\mathrm{NaCl}$ (resistivity $92.8 \Omega \mathrm{cm}$ ) of a 304 stainless steel strip modified by prior anodic treatment in metasilicate solution. The sample was polarized at $+0.40 \mathrm{~V}$ vs. $\mathrm{Ag} / \mathrm{AgCl} / 3 \mathrm{M} \mathrm{KCl}$ following the application of a cathodic pulse during $6 \mathrm{~s}$. The values of the cathodic polarizations are indicated in the plots referred to the $\mathrm{Ag} / \mathrm{AgCl} / 3 \mathrm{M} \mathrm{KCl}$ reference electrode. (A) Local ionic current densities detected at the SVET probe placed over the centre of the metal strip. (B) Total current flowing through the specimen. (C) SVET image of the strip after the application of cathodic pulse of $-1.40 \mathrm{~V}$ vs. $\mathrm{Ag} / \mathrm{AgCl} / 3 \mathrm{M} \mathrm{KCl}$ and subsequent anodic polarization at $+0.40 \mathrm{~V}$ vs. $\mathrm{Ag} / \mathrm{AgCl} / 3 \mathrm{M} \mathrm{KCl}$. The image represents $1775 \mu \mathrm{m} \times 2580 \mu \mathrm{m}$ in $X$ and $Y$ directions. Values of $Z$ axis: Ionic current, $\mu \mathrm{A}$ $\mathrm{cm}^{-2}$. Mean probe-substrate distance: $60 \mu \mathrm{m}$.

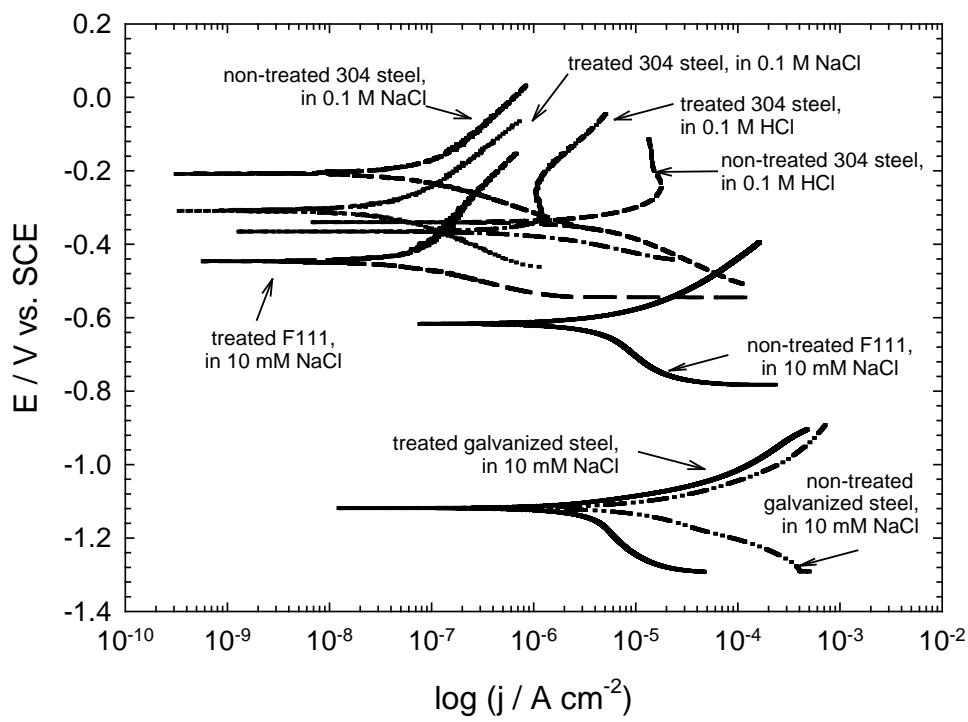

\section{Figure 7}

Typical Tafel plots of grade F111 steel, grade 304 stainless steel and galvanized steel samples immersed in the solutions indicated in the plot. Scan rate: $1 \mathrm{mV} \mathrm{s}^{-1}$. 